Los delitos de violación y estupro del artículo 365 bis Código Penal: Una racionalización desde el mandato de lex stricta y el principio de lesividad. Especial referencia a la introducción de dedos u otras partes del cuerpo José Ángel Fernández Cruz páginas $105-135$

\title{
LOS DELITOS DE VIOLACIÓN Y ESTUPRO DEL ARTÍCULO 365 BIS CÓDIGO PENAL: UNA RACIONALIZACIÓN DESDE EL MANDATO DE LEX STRICTA Y EL PRINCIPIO DE LESIVIDAD. ESPECIAL REFERENCIA A LA INTRODUCCIÓN DE DEDOS U OTRAS PARTES DEL CUERPO*
}

\author{
José Ángel Fernández Cruz**
}

\begin{abstract}
RESUMEN
El art. 365 bis $\mathrm{CP}$ constituye una de las últimas manifestaciones del modelo penal de seguridad ciudadana en nuestro Sistema Penal que, en esta ocasión, ha tenido como principales víctimas a los principios de legalidad y correspondencia con la realidad social. El desconocimiento de la realidad social por parte del legislador penal a la hora de describir el precepto in comento ha ocasionado una falta de certeza jurídica que, a la vez, ha derivado en una quiebra del mandato de lex stricta por parte de la mayoría de los tribunales penales chilenos. El presente artículo pretende, en la medida de lo posible, mitigar la manifiesta irracionalidad de este precepto a través de una interpretación alternativa desde el mandado de lex stricta y el principio de lesividad.
\end{abstract}

\section{PALABRAS CLAVES}

Delitos Sexuales, principio de legalidad, racionalidad del derecho penal

\footnotetext{
* Recibido el 27 de marzo de 2007; aceptada su publicación el 15 de abril de 2007. El presente trabajo toma como referencia un informe en derecho elaborado para la Defensoría Penal Pública de la X ${ }^{a}$ Región en el juicio del TOP de Puerto Montt de fecha 28 de junio de 2004. También quiero agradecer al prof. Cáceres los comentarios y matizaciones que me formuló con ocasión de la ponencia que de manera conjunta presentamos sobre esta cuestión en el XVII Congreso Latinoamericano de Derecho penal. Véase, la ponencia publicada en: Fernández Cruz, José Ángel y Cáceres Santibáñez, Rafael, «El nuevo delito de violación o estupro impropios del art. 356 bis CP chileno: una racionalización desde la perspectiva del bien jurídico», (en) XIII Congreso Latinoamericano de Derecho penal y Criminología, Guayaquil, octubre de 2005.

** Prof. Dr. de Derecho penal de la Facultad de Ciencias Jurídicas y Sociales de la Universidad Austral de Chile. E-mail: josefernandez@uach.cl
} 


\begin{abstract}
Section 365 bis of the Chilean Criminal Code is one of the latest manifestations of the law and order policy in our Criminal Justice System. In this occasion, it has mainly affected the principle of legality and its correspondence with social reality. A criminal justice lawmaker non-familiarized with social reality can create a lack of legal certainty and, consequently, a breach of the lex stricta mandate. A paradigmatic example of this is the typical description made of section 365 bis and its interpretation by most criminal courts. This paper seeks, to the extent possible, to mitigate such manifest irrationality.
\end{abstract}

\title{
KEY WORDS
}

Sexual offenses - principle of legality- rationality in criminal law

\section{Introducción: el mandato de lex certa y el principio de correspondencia con la realidad}

En enero de 2004, producto de la gran conmoción social causada por la revelación de una serie de casos de abusos sexuales perpetrados contra menores ${ }^{1}$ en los que supuestamente habían participado destacados políticos, el CP fue objeto de diversas modificaciones que alteraron los parágrafos 5 y 6 del título VII de su libro II, modificaciones que en algunos casos pasaron por un incremento de las penas y en otros por la creación de nuevos tipos penales. Entre estas últimas encontramos la figura del artículo 365 bis $\mathrm{CP}^{2}$.

La incorporación de este precepto a nuestro acervo penal ha generado un grave problema de interpretación o subsunción de una determinada conducta sexual: si la introducción de partes del cuerpo distintas al pene puede incluirse en algunas de sus modalidades típicas (la introducción de objetos o de animales o de parte de ellos). El presente estudio pretende abordar este problema de interpretación, además de otras cuestiones dogmáticas que suscita este precepto. Pero antes resulta necesario mencionar el marco político criminal sobre el cuál se van a asentar las conclusiones de este análisis.

La historia legislativa de esta reforma resume, quizá como ninguna otra, la mayoría de las

\footnotetext{
1 El conocido caso Spiniak tuvo como punto de partida la detención del empresario Claudio Spiniak como organizador de una red de pedofilia y una supuesta participación de connotados políticos. Después de asistir a un sin fin de declaraciones y desmentidos, la justicia determinó el sobreseimiento definitivo de la causa respecto de los parlamentarios inicialmente implicados, que derivó incluso a la condena de varios involucrados por el delito de falso testimonio. Finalmente, los partícipes de esta red de pedofilia fueron condenados por los delitos de estupro, violación, abuso sexual, facilitación a la prostitución, producción de material pornográfico y asociación ilícita.

$2 \quad$ Ley N 19.917 publicada en el Diario Oficial de 14 de enero de 2004.
} 
Los delitos de violación y estupro del artículo 365 bis Código Penal: Una racionalización desde el mandato de lex stricta y el principio de lesividad. Especial referencia a la introducción de dedos u otras partes del cuerpo

características del modelo penal de seguridad ciudadana. A mayor abundamiento podemos destacar la prevalencia del sentimiento de inseguridad ciudadana, el populismo y politización, la pérdida de influencia de los grupos de $\operatorname{expertos}^{3}$ y la sustantividad de los intereses de la víctima como los principales factores que han incidido en la articulación típica del art. 365 bis $\mathrm{CP}^{4}$. Consecuentemente, la aplicación del citado modelo penal ha derivado en la quiebra de varios principios básicos penales ${ }^{5}$, entre los que destacamos, el principio de correspondencia con la realidad y el principio de legalidad, principios que, como veremos a continuación, se encuentran estrechamente relacionados.

\section{El principio de correspondencia con la realidad}

Un debate político criminal debe sustentarse en un previo estudio empírico-social. El principio de correspondencia con la realidad constituye uno de los principios penales estructurales de la política criminal: estamos ante uno de los principios de racionalidad derivados de la modernidad, donde frente a actitudes morales similares a consideraciones religiosas o mágicas ya superadas, predomina una aproximación empírica en el conocimiento de las relaciones sociales ${ }^{6}$. Además, el cumplimiento del principio de lesividad exige el previo conocimiento de la realidad a fin de determinar las conductas más graves en una determinada sociedad. En este sentido, no debemos olvidar que el derecho penal está destinado -dentro de unos límites éticos, muchos de ellos constitucionalizados- a resolver un determinado conflicto social. Por tanto, uno de los presupuestos, junto a la legitimación ética y democrática, que debe tener presente una política criminal sustentada en un Estado social reside precisamente en el

Normalmente la falta de influencia de los grupos de expertos penales deriva en una quiebra del principio de proporcionalidad de las penas, principio asentado en el acervo político criminal de la práctica totalidad de la doctrina. Así, véase como los expertos criticaron la penalidad propuesta, arguyendo, entre otras razones, su incongruencia con otras figuras penales, como en el caso del homicidio; la falta de tiempo desde el anterior aumento de penas, a través de la reforma de 1999, para establecer si las penas son adecuadas; y la desconfianza del legislador hacia los criterios judiciales para aplicar los beneficios de la ley 18.216. Véase el Primer informe de la Comisión de Constitución, Legislación, Justicia y Reglamento del Senado, de 10 de septiembre de 2003, p. 19 y sgtes., contenido en el Boletín N. ${ }^{\circ}$ 2906-07, disponible en: http://www.bcn.cl.

$4 \quad$ Véase en extenso, Garland, David, The culture of control, Chicago: The University of Chicago Press, (2001); Díez Ripollés, José Luis, «El nuevo modelo penal de la seguridad ciudadana», (en) Revista Electrónica de Ciencia Penal y Criminología (RECPC), núm. 06-03, (2004). Disponible en internet: http://criminet.ugr.es/ recpc/06/recpc06-03.pdf.; Fernández Cruz., José Ángel, «El Nuevo Código Penal: una lucha por el discurso de la criminalidad», (en) Polít. crim. n 1-A5, p. 1-30, (disponible en internet: http://www.politicacriminal.cl/ n_01/pdf_01/a_5.pdf.).

$5 \quad$ El art. 365 bis CP también comparte con el resto de los delitos contra la libertad o indemnidad sexual su desprecio por el principio de proporcionalidad de las penas. La ausencia de una vinculación típica entre la lesión o puesta en peligro del bien jurídico protegido (libertad e indemidad sexuales) permite formalmente, por ejemplo, que la introducción con violencia de un lapicero en la boca de la víctima merezca una pena en abstracto de cinco años y un día a quince años.

6 Díez Ripollés, José Luis, La racionalidad de las leyes penales, Madrid: Trotta, (2003), p. 145. 
contexto social donde se desarrolla la disfunción mecedora de una protección penal ${ }^{7}$.

Los principios y garantías penales cobran relevancia en función de la gravedad de la pena, es decir, la necesidad de un conocimiento de la realidad social aumenta en consonancia con la gravedad de las penas. Para hacer efectiva esta obligación en la fase de incriminación primaria, tenemos que recordar que el legislador tiene el auxilio de una ciencia dedicada exclusivamente a estos menesteres: la Criminología. Sin duda, constituye un privilegio para el Derecho penal -que por cierto las restantes ramas del Ordenamiento jurídico no pueden disfrutar, al menos, con la misma intensidad- contar con la ayuda de la Criminología. Por esta razón, resulta más criticable e incomprensible el desconocimiento de la realidad social por parte del legislador penal.

La descripción típica del art. 365 bis CP refleja un claro desprecio a la realidad social ya que no tomó en cuenta una las principales modalidades de abusos sexuales cometidos en Chile (la introducción de los dedos en la vagina o ano de la víctima) que político criminalmente ameritaría una discusión sobre su configuración como un tipo de abusos sexuales calificados. En otras palabras, nuestros representantes políticos no resolvieron una disfunción social, y no cabe duda, porque así lo constata la información criminológica, que la introducción de dedos en la vagina o ano de la víctima, especialmente en menores de edad, constituye una de las formas más comunes de abusos sexuales en Chile. El legislador debería haber determinado expresamente si la introducción de dedos constituía o no una modalidad comisiva del art. 365 bis $\mathrm{CP}$, sin perjuicio de incluir otras modalidades comisivas como la introducción de objetos y animales.

La falta de correspondencia con la realidad social comporta una tensión entre los mandatos de lex certa y lex stricta. Evidentemente, la omisión de la introducción de partes del cuerpo distintas del pene como modalidad comisiva conlleva necesariamente a que los tribunales penales deban preguntarse si, por ejemplo, la introducción de un dedo puede considerarse como una suerte de objeto o animal. La falta de certeza jurídica -derivada de una falta de correspondencia con la realidad social- supone una innecesaria presión político criminal hacia los tribunales de justicia, que puede derivar en una vulneración del mandato de lex stricta.

\section{Las relaciones entre los mandatos de lex certa y lex stricta}

El principio de legalidad constituye uno de los principales límites al Ius puniendi, y por

Fernández Cruz, José Ángel, «Tráfico de drogas: ética, realidad social y discurso», (en) Derecho penal y Criminología como fundamento de la Política criminal. Estudios en homenaje al profesor Alfonso Serrano Gómez, Madrid: Dykinson, (2006), p. 1184.

8 Zaffaroni, Eugenio Raúl (et alii), Derecho Penal. Parte General, (2 $2^{\mathrm{a}}$ ed.), Buenos Aires: Ediar, (2002), p.717. 
Los delitos de violación y estupro del artículo 365 bis Código Penal: Una racionalización desde el mandato de lex stricta y el principio de lesividad. Especial referencia a la introducción de dedos u otras partes del cuerpo

tanto, una garantía política del ciudadano frente a los abusos del poder punitivo ${ }^{8}$. Si bien, estamos ante el límite con una mayor protección jurídico-constitucional, la posibilidad de una extralimitación o quiebra del principio de legalidad continúa siendo uno de los principales peligros del ciudadano frente al Estado. Pero como manifiesta JAKOBS, el principio de sujeción a la ley forma parte de aquellos preceptos constitucionales cuya aplicación o interpretación puede llegar a complicarse hasta el punto de que fracasan en la práctica o la práctica fracasa en ellos. Por esta razón, una interpretación orientada no a la pureza de las ideas, sino a la eficacia práctica de la norma, no puede exigir ni una completa taxatividad o determinación de las normas penales, ni el mismo rigor de certeza en todas las normas penales ${ }^{9}$.

El mandato de determinación del hecho punible, también denominado mandato de certeza o lex certa, podemos derivarlo de dos principios fundamentales en el derecho penal contemporáneo: el principio de legalidad -que contiene un mandato material de determinacióny el principio de responsabilidad por el hecho -paradigma de la prohibición de castigar el carácter o modo de ser que se propugnó por la teoría de los tipos de autor- ${ }^{10}$.

El mandato de lex certa suele estudiarse por la doctrina desde dos perspectivas: la primera agota su misión requiriendo al legislador claridad y precisión en la formulación de los preceptos; la segunda, además, incluye la protección del ciudadano frente a la arbitrariedad del poder judicial.

Esta última postura aboga por un contenido pluridimensional del principio de determinación, es decir, que abarque tanto la técnica de legislar como la técnica de aplicación. En cambio, desde la primera perspectiva, la finalidad de acotamiento del arbitrio judicial no se deriva de la exigencia de certeza sino de la prohibición de analogía insita en la exigencia de lex stricta, y por lo tanto, estableciendo una separación entre la creación y aplicación de las normas penales. Por ende, este último de punto de vista, dirige el mandato de taxatividad al legislador, y en concreto al momento de configuración los tipos penales. Nuestra posición se muestra a favor de una cuatriparticíon de las exigencias derivadas del principio de legalidad.

La diferenciación entre lex certa y lex stricta pone de manifiesto los estadios temporales en el desarrollo del principio de legalidad; la primera implica la exigencia al legislador de definir de forma clara y comprensible los elementos integrantes en el tipo penal; la segunda

Jakobs, Günther, Derecho penal. Parte General. Fundamentos y teoría de la imputación, (2ª ed.), Madrid: Marcial Pons, (1997), p. 94.

10 Las consideraciones que a continuación se expresan sobre el contenido del mandato de lex certa y sus relaciones con el mandato de lex stricta han tomado como referencia el siguiente artículo doctrinal: Fernández, Cruz, José Ángel, «Naturaleza y contenido del mandato de lex certa en la Doctrina del Tribunal Constitucional», (en) Revista de la Facultad de Ciencias jurídicas y Sociales de la Universidad Austral, (1999), p. 141-151 (disponible en Internet: http://www.scielo.cl/scielo.php). Véase también la bibliografía citada en el mencionado artículo. 
supone la sumisión, o mejor dicho, el punto de partida imprescindible, a la hora de interpretar y aplicar el juez estos tipos ya configurados.

Como consecuencia de lo anterior, se pone de manifiesto la escala jerárquica entre ambas exigencias, que no es otra que la superioridad de la exigencia de certeza impuesta al legislador. Y no puede ser de otro modo en nuestro sistema político, donde debe recordarse que la ley es expresión de la voluntad popular y se espera, de acuerdo con el principio de exclusiva protección de bienes jurídicos, que sean los propios ciudadanos quienes decidan qué debe protegerse penalmente, a lo que habría que añadir, que sean también los que determinen cómo y de qué forma quieren protegerlos. Una reunión de estas dos exigencias en un único mandato puede tentar a los intérpretes del derecho a subsanar las posibles deficiencias en la determinación de los tipos penales mediante interpretaciones que sobrepasan su legitimidad constitucional. Esta posición supedita la propia seguridad jurídica a una supuesta eficacia de las normas jurídicas.

Esta separación no supone ningún obstáculo para establecer las repercusiones del mandato de certeza sobre el mandato de lex stricta, puesto que, aunque operan en ámbitos diferentes, el cumplimiento del mandato de certeza constituye el presupuesto básico para llevar a buen fin las exigencias derivadas del mandato de aplicación estricta de la ley.

En conclusión, cuatro son las exigencias derivadas del principio de legalidad:

1. El mandato de escritura y la Reserva de Ley en materia penal (Lex scripta).

2. La expresa prohibición retroactividad de las leyes penales que crean nuevos delitos o agravan su punición (Lex praevia).

3. El mandato de determinación o taxatividad que se concreta en la tipicidad del hecho y en la determinación legal de la pena (Lex certa).

4. La prohibición de analogía por parte de los jueces y tribunales, y, en general, como la exigencia en el cumplimiento escrupuloso del principio de legalidad a la hora de aplicar la Ley penal (Lex stricta).

Esta obsesión por una postura diferenciadora en relación con la tesis a favor de la cuatripartición de los mandatos derivados del principio de legalidad, obedece a la pretensión de hacer realidad, desde la misma creación de la norma, un auténtico estado de seguridad jurídica. El mandato de determinación dirigido al legislador no tiene en un primer momento la finalidad de cercenar o impedir el arbitrio judicial, sino que es una finalidad preventivo general dirigida a los ciudadanos, y el mandato así entendido debe suponer que éstos sean capaces de aprehender el contenido normativo, antes de cualquier pronunciamiento interpretativo jurisprudencial, al menos respecto de su contenido esencial. 
Los delitos de violación y estupro del artículo 365 bis Código Penal: Una racionalización desde el mandato de lex stricta y el principio de lesividad. Especial referencia a la introducción de dedos u otras partes del cuerpo

Por supuesto que el cumplimiento del mandado de determinación no supone cercenar la necesaria abstracción de las normas penales y la necesaria interpretación por parte de los operadores jurídicos, sino que la descripción típica debe permitir con cierta seguridad que a través de la interpretación se determine qué conductas son prohibidas. Ahora bien, qué debemos entender por cierta seguridad en cada descripción típica supone uno de los principales retos del cumplimiento material del principio de legalidad, cuestión quizá de irresoluble solución, pero el cumplimiento de otros principios penales ayuda a su consecución. Así, el respeto del mandato de correspondencia con la realidad contribuye a concretar esta cierta seguridad ya que la descripción típica se ocupa de las principales y más comunes disfunciones sociales.

No obstante, profundizando en lo manifestado con anterioridad, en un segundo momento -en la fase de aplicación- el mandato de certeza tiene la finalidad de cercenar el arbitrio judicial para que, de esta manera, puedan los órganos jurisdiccionales cumplir el mandato de lex stricta o prohibición de analogía. Lo anterior nos plantea la cuestión de si muchos de los problemas de inseguridad que a primera vista parecen tener como causa una extralimitación en la interpretación judicial, quizás sean realmente fruto de una falta de determinación legislativa.

Así, el intérprete, y en especial los jueces, a la hora de aplicar un tipo penal a un caso concreto deben descender de la generalización de la ley a lo específico del caso concreto, pero lo que tienen prohibido es aumentar el nivel de generalización de los elementos positivos del tipo penal. Además, la interpretación penal debe ser tanto más restrictiva cuanto mayor sea la gravedad de la pena ${ }^{11}$, como sucede con las penas descritas en el art. 365 bis CP.

Tras estas breves, pero necesarias consideraciones sobre los principios de legalidad y correspondencia con la realidad social pasamos a abordar el estudio del art. 365 bis CP, y en especial, su ámbito de aplicación.

\section{Naturaleza jurídica del art. 365 bis y su ubicación sistématica}

Como manifiesta el Informe de la Defensoría Penal Pública sobre la ley $19.927^{12}$, el art. 365 bis $\mathrm{CP}$ «aún cuando está tratado en el párrafo $6^{\circ}$, y por tanto debería entenderse que se trata de un abuso sexual especialmente agravado, algunos supuestos tienen la misma pena que la violación». Nuestra opinión da un paso más en esta dirección, y consideramos que nos encontramos ante un ejemplo de una deficiente técnica legislativa.

11 Por todos en la doctrina alemana: Schmidt, Rolf, Strafrecht Allgemeiner Teil. Grundlagen der Strafbarkeit Aufbau des strafrechtlichen Gutachtens, (4 ed.) Bremen, (2005), p. 12.

12 Véase, Comentarios a la ley 19.927 de Delito de pornografía infantil, elaborado por la Defensoría Penal Pública en: http://www.defensoriapenal.cl. 
Con independencia de la ubicación sistemática de este delito, que en ningún caso debe constituir un criterio determinante a la hora de establecer su naturaleza jurídica, consideramos que nos encontramos ante una figura delictiva que tipifica supuestos más cercanos a la violación y el estupro. Desde la penalidad impuesta, la valoración de la conducta, las modalidades típicas y la remisión expresa a los art. 361 y $363 \mathrm{CP}$, debemos concluir que la naturaleza jurídica de esta figura delictiva se asemeja más a la violación o al estupro que al abuso sexual ${ }^{13}$. A pesar de la referencia expresa al art. 366 ter $\mathrm{CP}$, ni la conducta típica ni la naturaleza jurídica del art. 365 bis CP pueden determinarse a través de este precepto. El art. 365 bis CP describe una acción de especial «significación sexual y relevancia» que valorativamente se asemeja más a las violaciones y estupros clásicos. No obstante, el art. 366 ter $\mathrm{CP}$ puede limitar ciertas introducciones de objetos que no posean una «significación sexual y relevancia» ${ }^{14}$.

Como conclusión, denominamos esta figura delictiva como violación o estupro impropios.

\section{Tipicidad objetiva: delimitación del ámbito de aplicación}

\section{El bien jurídico protegido (remisión)}

Los delitos de estupro y violación tipificados en el art. 365 bis cumplen, sin duda, con los requisitos derivados del concepto material de delito. Es decir, el art. 365 bis tipifica agresiones que podemos considerar graves para un bien jurídico fundamental para la convivencia social. De esta manera, el bien jurídico coincide con los protegidos en los art. 361, 362 y 363 CP. Sin poder entrar en el profuso debate sobre cuál es el bien jurídico protegido en las citadas figuras penales que, como resulta conocido, se centra entre la libertad, la integridad y la indemnidad sexual ${ }^{15}$, el estudio del ámbito de aplicación del tipo penal arroga la protección de otros bienes jurídicos protegidos. A fin de facilitar la compresión del carácter pluriofensivo del art. 365 bis $\mathrm{CP}$ remitimos el estudio de ámbito de protección material a un apartado posterior.

13 A tenor de estas consideraciones, consideramos sistemáticamente más apropiado la propuesta de modificación del inciso segundo del art. 361 CP realizada por los Diputados señor Walker y señora Guzmán, donde se incluía como nueva modalidad comisiva, junto al acceso carnal por vía vaginal, anal o bucal, la introducción de «cualquier elemento». Véase el Primer informe de la Comisión de Constitución, Legislación y Justicia de la H. Cámara de Diputados, de 4 de septiembre de 2002, p. 41 y sgtes., contenido en el Boletín N. ${ }^{\circ}$ 2906-07, disponible en: http://www.bcn.cl. El CP español adopta esta propuesta de sistematización. Así, los arts. 179 y 183 CP español equiparan dentro de la categoría de agresiones sexuales y abusos sexuales el acceso carnal con la introducción de miembros corporales u objetos.

14 Véase infra, III, 2.

15 Véase en extenso, Diez Ripollés, José Luis, «El objeto de protección del nuevo derecho penal sexual», (en) Revista de Derecho penal y Criminología (2a época), núm. 6 (2000), p. 69-101; Véase en extenso, Rodríguez Collao, Luis, Delitos sexuales: de conformidad con las modificaciones introducidas por la ley No. 19.617 de 1999, Editorial Jurídica de Chile, (2000), p.20-56. 
Los delitos de violación y estupro del artículo 365 bis Código Penal: Una racionalización desde el mandato de lex stricta y el principio de lesividad. Especial referencia a la introducción de dedos u otras partes del cuerpo

\section{Delimitación de las modalidades típicas: la introducción de partes del cuerpo distintas al pene}

El principal escollo típico que este precepto presenta en la práctica reside en delimitar su ámbito de aplicación, en especial, respecto a sus distintas modalidades típicas. Así, una de las primeras causas bajo la vigencia de la ley 19.927 ya planteó, como era previsible, la cuestión de si resultaba subsumible en el art. 365 bis CP, la introducción de un miembro o parte del cuerpo distinto al pene en la vagina, ano o boca de la víctima ${ }^{16}$.

Para resolver esta cuestión debemos tener presente las siguientes consideraciones: en primer lugar, estamos ante una subsunción de un supuesto concreto en un tipo penal; en segundo lugar, este hecho concreto o modalidad comisiva no está expresamente tipificado en el art. 365 bis CP. Por lo tanto, estamos ante un problema de legalidad penal en la fase de interpretación, es decir, debemos ubicar este problema en el seno de los límites del denominado mandato de lex stricta.

El ámbito de aplicación de esta figura delictiva se centra en dos problemas fundamentales: el primero, reside en delimitar qué introducciones de objetos pueden considerarse típicas; y el segundo problema afronta la cuestión de si la introducción de partes o extremidades del cuerpo distintas del pene en la vagina, ano o boca de la víctima se puede subsumir en algunas de las modalidades típicas del art. 365 bis CP.

\section{A) Modalidades expresamente tipificadas}

De la lectura del art. 365 bis $\mathrm{CP}$ podemos concluir que formalmente tipifica dos modalidades comisivas:

a) Introducción de objetos de cualquier índole, por vía vaginal, anal o bucal.

b) Utilización de animales o partes de ellos en una acción sexual. En este caso debemos establecer si resulta típica cualquier acción sexual donde se utilicen animales. Entendemos que, tanto de la dicción literal del precepto, como del desvalor del hecho de esta modalidad, sólo será típica la introducción de animales o parte de ellos en la vagina, ano o boca de la víctima $^{17}$. Si bien la inclusión de esta modalidad comisiva tuvo seguramente como referencia una de las formas de tortura de la dictadura militar, llama poderosamente la

$16 \quad$ STJOP de Puerto Montt de fecha 28 de junio de 2004 (RIT-1-2004).

17 La inclusión de animales o parte de ellos como objeto de comisión fue propuesta por la Diputada señora Soto. Véase el Primer Informe de la Comisión de Constitución, Legislación y Justicia de la H. Cámara de Diputados, de 4 de septiembre de 2002, p. 43 y sgtes., contenido en el Boletín N. ${ }^{\circ}$ 2906-07, disponible en: http://www.bcn.cl 
atención que el legislador se ocupara de una disfunción que en la actualidad no tiene ninguna incidencia, en contraposición con la introducción de partes del cuerpo distinta del pene.

En cuanto a la «introducción de objetos», podemos traer a colación las palabras de SERRANO GÓMEZ respecto del delito de violación español (art. 179 CP): «el texto se limita a hacer referencia a objetos, sin especificar lo que a efectos de este delito se entiende como tales. Si se tiene en cuenta que objeto equivale a cosa, las posibilidades son inagotables, con lo que una vez más la inseguridad es patente» ${ }^{18}$.

Sin duda, el legislador podría haber delimitado con mayor certeza la lesión o puesta en peligro del bien jurídico protegido, pero creemos que a través de la interpretación del art. 365 bis $\mathrm{CP}$ resulta posible limitar su ámbito de aplicación.

Una primera posibilidad de restricción del ámbito de aplicación reside en el art. 366 ter $\mathrm{CP}$, que como hemos manifestado, a pesar de su dicción literal, no afecta a la naturaleza del art. 365 bis CP. Esta interpretación legal del abuso sexual cumple, a nuestro parecer, una función límite sobre el universo de conductas que formalmente podrían encajar en la descripción típica del art. 365 bis CP. Así, la introducción de objetos de cualquier índole y la utilización de animales tendría que constituir un «acto de significación sexual y de relevancia» ${ }^{19}$.

Una segunda posibilidad de restricción del ámbito de aplicación es acudir a la concreción de la lesión o puesta en peligro de los bienes jurídicos protegidos en el art. 365 bis $\mathrm{CP}^{20}$.

Por último, las exigencias derivadas de la tipicidad subjetiva también pueden limitar el ámbito de aplicación del art. 365 bis CP, cuestión que se abordará en un apartado posterior.

\section{B) La introducción de otras partes distintas al pene como modalidad subsumible en el art. 365 bis $\mathbf{C P}$}

\footnotetext{
18 Serrano Gómez, Alfonso, Derecho penal. Parte Especial, (10 ed.) Madrid: Dykinson, (2002), p. 208. El Diputado señor Bustos, ya en la tramitación de ley, estimó demasiado amplio el término «objetos materiales de cualquier índole». Véase el Primer informe de la Comisión de Constitución, Legislación y Justicia de la Cámara de Diputados, de 4 de septiembre de 2002, p. 44 y sgtes., contenido en el Boletín N. 2906-07, disponible en: http://www.bcn.cl

19 Los representantes del Ejecutivo postularon en la tramitación de la ley 19.927 la calificación de estas conductas como abusos sexuales agravados proponiendo agregar un inciso final a los artículos 366 y 366 bis, para así evitar la sanción de conductas inofensivas, por ejemplo, en el ámbito de la medicina. Véase el Primer informe de la Comisión de Constitución, Legislación y Justicia de la H. Cámara de Diputados, de 4 de septiembre de 2002, p. 44 y sgtes., contenido en el Boletín N. ${ }^{\circ}$ 2906-07, disponible en: http://www.bcn.cl 
Los delitos de violación y estupro del artículo 365 bis Código Penal: Una racionalización desde el mandato de lex stricta y el principio de lesividad. Especial referencia a la introducción de dedos u otras partes del cuerpo

Cuando nos enfrentamos ante un supuesto que no está tipificado expresamente como modalidad típica en un delito que en la descripción legal acota expresamente las modalidades comisivas (delito con medios legalmente determinados ${ }^{21}$ ), debemos resolver si puede subsumirse a través de la interpretación en algunos de los medios legalmente establecidos. Como primera conclusión, podemos afirmar, en relación con esta clase de delitos, que los operadores jurídicos poseen un menor margen de interpretación en contraposición con los delitos resultativos.

En estos casos, dos son los principios interpretativos que entran en conflicto. Por una parte, el denominado principio de autonomía en la interpretación del Derecho penal, que concurre cuando ciertos términos son definidos de una manera diferente - conforme al sentido del tipo y el bien jurídico protegido- a la interpretación realizada en el lenguaje común, o incluso, a la realizada por otras ramas del ordenamiento jurídico: el concepto de «cosa mueble» en los delitos de hurto y robo constituye el ejemplo paradigmático en este último caso. Y por otra parte, la interpretación restrictiva o mandato de lex stricta que hemos abordado con anterioridad.

Pues bien, el caso que nos ocupa constituye uno de estos supuestos. Así, el concepto de objeto que ofrece la RAE no comprende partes del cuerpo humano, por lo que deberemos establecer, de acuerdo con los límites a la interpretación de los tipos penales, si resulta posible aplicar el principio de autonomía en la interpretación del derecho penal y, de esta manera, subsumir las partes del cuerpo distintas del pene en el concepto «objeto de cualquier índole».

El conflicto entre estos dos principios de interpretación constituye una manifestación de la problemática entre interpretación extensiva y la analogía. La doctrina diferencia entre interpretación extensiva de los tipos penales y la analogía. La primera radica en la búsqueda de un sentido del texto legal que se halle dentro de su «sentido literal», mientras que la segunda, supone la aplicación de una ley penal a un supuesto no comprendido en ninguno de los sentidos posibles de su letra, pero análogo -valorativamente similar- a otros sí comprendidos en el texto legal $^{22}$.

De acuerdo con la protección constitucional del principio de legalidad debemos afirmar categóricamente que el principio de autonomía de interpretación del derecho penal debe respetar el mandato de lex stricta, entendido como la prohibición de analogía por parte de los jueces y tribunales, y en general, como la exigencia en el cumplimiento escrupuloso del principio de legalidad a la hora de aplicar la ley penal. No obstante, en la actualidad existe un acuerdo

\footnotetext{
21 La limitación de los modos de ejecución de los delitos con medios legalmente determinados debería responden al carácter fragmentario del derecho penal, seleccionando las formas comisivas más graves o peligrosas, pero en ocasiones la selección es un tanto arbitraria y no responde a esos criterios. Luzón Peña, Curso de Derecho penal, Madrid: Universitas, (1996), p. 308. 
unánime en que la concepción mecanicista del juez a la hora de aplicar la ley penal al caso concreto es impracticable, debido principalmente al carácter intrínsecamente relativo de la taxatividad de la ley penal. A mayor abundamiento, desde una perspectiva teórica existe una considerable unanimidad, primero, en permitir una interpretación extensiva de los tipos penales, y segundo, en prohibir una interpretación analógica de los tipos penales en contra del reo. El problema se presenta a la hora de compaginar las anteriores afirmaciones a los casos que la práctica presenta. Esto trae como consecuencia, la existencia de numerosas teorías que intentan establecer los requisitos que son necesarios para permitir una interpretación extensiva de los tipos penales, y que a la vez respeten los mandatos del principio de legalidad. De esta manera, para algunos autores la subsunción de un caso concreto a un tipo penal supone una quiebra del referido mandato, y para otros, por el contrario, estamos dentro los límites que impone el principio de legalidad.

Por lo anteriormente señalado, entendemos que la mejor manera de determinar si el caso que nos ocupa cumple o no el mandato de lex stricta es acudir a aquellas teorías de mayor aceptación, y a la vez más divergentes sobre los límites en la interpretación de lo tipos penales. Así acudiremos, en primer lugar, a la propuesta liderada por ROXIN, y segundo lugar, aplicaremos una posición más extensiva respecto a estos límites, defendida por JAKOBS. Sin duda, esta técnica de fundamentación jurídico-penal ofrece mayores garantías de legitimación penal en la fase de incriminación secundaria.

Pero antes de abordarlas, debemos recalcar que ambas posiciones otorgan un valor segundario a la teoría subjetiva (voluntad del legislador) en el marco de un Estado Democrático de Derecho. Este valor secundario que la mayoría de la doctrina otorga a la teoría subjetiva resulta de especial importancia en el caso que nos ocupa, ya que en la discusión parlamentaria sobre el art. 365 bis CP se hizo expresamente referencia a la introducción de dedos u otras partes del cuerpo como un supuesto subsumible en la introducción de «objetos de cualquier índole», referencia que ha servido posteriormente como fundamento de la mayoría de la jurisprudencia de los $\mathrm{TJOP}^{23}$ para subsumir la introducción de partes del cuerpo distintas del pene.

Las exposiciones de motivos, en no pocas ocasiones, contradicen lo realmente preceptuado en la ley; las afirmaciones en los debates son, a lo sumo, indicios de las presuposiciones de algunos parlamentarios que, incluso por falta de conocimiento técnico o de interés carecen de la suficiente información sobre el objeto de la regulación ${ }^{24}$; la denominada voluntas legislatoris, también en no pocas ocasiones, resulta realmente un conglomerado de voluntades, donde participan los autores del proyecto o comisiones de codificación, el ministerio o gobierno que

\footnotetext{
23 Véase, infra $V$. Tratamiento jurisprudencial.

24 Jakobs, Derecho penal..., cit., p. 94.
} 
Los delitos de violación y estupro del artículo 365 bis Código Penal: Una racionalización desde el mandato de lex stricta y el principio de lesividad. Especial referencia a la introducción de dedos u otras partes del cuerpo

lo impulsó, diversos grupos parlamentarios, por lo que resulta inviable hablar de una única voluntas legislatoris. Pero, sin duda, la principal razón que otorga un valor secundario a la teoría subjetiva reside en su inviabilidad en una democracia por falta de determinación vinculante de las presuposiciones de las respectivas mayorías parlamentarias ${ }^{25}$. Recordemos que el principio de legalidad, es decir las leyes penales y no sus previas deliberaciones, supone la principal garantía que el Ordenamiento Jurídico otorga a los ciudadanos de la República. Por lo tanto, la interpretación histórica del art. 365 bis CP no puede constituir el factor determinante en la resolución del caso que nos ocupa y, a lo sumo, sirve de apoyo para establecer el sentido de la ley.

\section{a) El «sentido literal posible en lenguaje corriente» como límite de la interpretación}

Esta posición trata de conciliar el sometimiento del juez al imperio de la Ley y el hecho de que el contenido de un precepto penal es determinado, en el sentido de una claridad excluyente de dudas, mediante la interpretación judicial, que a juicio de este enfoque doctrinal debe realizarse a través de la búsqueda del sentido literal posible en lenguaje corriente del texto de la ley. Para llevar a cabo este cometido el intérprete puede acudir al significado literal más próximo, a la concepción del legislador, al contexto sistemático legal o al propio fin de la ley (interpretación teleológica) ${ }^{26}$.

La vinculación del mandato de lex stricta con el límite del «sentido literal posible del lenguaje corriente», como manifiesta ROXIN, no es «en absoluto arbitraria, sino que se deriva de los fundamentos jurídico-políticos del principio de legalidad ${ }^{27}$. El principio de legalidad como garantía del ciudadano sólo puede cumplirse si el intérprete usa el mismo método de interpretación que acudiría el ciudadano, asegurándose de esta manera un mayor grado de cumplimiento del fin preventivo general del Derecho penal.

Una importante consecuencia que podemos extrapolar de esta teoría radica en la inconstitucionalidad de aquellas interpretaciones derivadas del principio de autonomía de interpretación del Derecho penal divergentes con aquéllas derivadas del «sentido literal posible en el lenguaje común». Por el contrario, serán validas las interpretaciones que establezcan un contenido diferente de otras ramas del Ordenamiento jurídico, pero conformes con el «sentido literal posible en el lenguaje común», como es el caso del concepto de «bien mueble» en los delitos de hurto y robo.

Una interpretación extensiva o analógica que vaya más allá del sentido literal posible de

\footnotetext{
25 Jakobs, Derecho penal..., cit., p. 94.

26 Roxin, Claus, Derecho Penal. Parte General. Fundamentos. La estructura de la Teoría del Delito, (Tomo I), LUZÓN PEÑA (et alii) (trads. y notas), Madrid: Civitas, p. 147-158.

27 Roxin, Claus, Derecho Penal..., cit., p. 148.
} 
un término en el lenguaje común, sólo sería admisible si se tratara de una interpretación auténtica de la propia ley, donde se utiliza un concepto con un significado ampliatorio que desborda su sentido literal posible en el lenguaje usual. Así sucede por ejemplo con la definición legal de «fuerza en las cosas» en el robo, que incluye supuestos, como el escalamiento, que no encajan en el sentido de fuerza en el lenguaje normal ${ }^{28}$.

Analizada someramente esta posición doctrinal, podemos ya resolver si la introducción de alguna parte del cuerpo de una persona distinta del pene está dentro de lo que el «sentido literal posible del lenguaje corriente» considera como «objetos de cualquier índole» o como parte de un «animal». Y la respuesta debe ser negativa. Los conceptos de objeto y animal, no sólo no caben en el citado sentido literal sino que estamos ante antónimos de un ser humano, a saber, podemos definir a un ser humano por exclusión de los conceptos de objeto y animal.

Ahora bien, la interpretación extensiva de los tipos penales no debe confundirse con las valoraciones de lege ferenda sobre la posible tipificación de un conflicto social. Así, es posible que la mayoría de los operadores jurídicos y de la ciudadanía consideren que la introducción de partes distintas del pene deba tener una semejante respuesta penal respecto de aquéllos hechos tipificados en el art. 365 bis CP, pero la solución a esta necesidad de mayor protección debe ser subsanada por nuestros legítimos representantes políticos.

\section{b) La generalidad y pertenencia a un sistema como límite a la interpretación penal}

Pasamos a tratar una posición que postula un mayor margen de interpretación en los tipos penales. JAKOBS, uno de sus principales defensores, mantiene que el «límite a la interpretación no es el sentido que tienen los conceptos del Derecho, sino aquel que se les pueda atribuir». Esta afirmación, continua el autor, no significa una plena arbitrariedad por parte de los intérpretes del Derecho penal, ya que la interpretación de un elemento o término jurídico penal no debe perturbar el sistema de interpretación que el usus jurídico penal ha establecido en una determinada cultura jurídico penal; en palabras del conocido penalista alemán: «la interpretación debe ser generalizable sin perturbar el sistema en relación con problemas interpretativos análogos». Así, el autor ejemplifica esta afirmación con la autoría en los delitos contra la Administración Pública, al afirmar que a pesar de la designación masculina -el funcionario público- pueden ser también autores las mujeres. Esta regla de interpretación no rompería el sistema de interpretación ya que resulta aplicable a otros supuestos análogos (delitos contra la Administración de Justicia). En cambio, en otros delitos, como los relativos a la protección de la libertad sexual, la autoría sólo puede ser masculina porque precisamente estos casos no son análogos a los referidos delitos especiales propios $^{29}$.

\footnotetext{
28 Luzón Peña, Diego-Manuel, Curso de Derecho penal..., cit., p. 163-171.

29 Jakobs, Derecho penal..., cit., p. 103-104.
} 
Los delitos de violación y estupro del artículo 365 bis Código Penal: Una racionalización desde el mandato de lex stricta y el principio de lesividad. Especial referencia a la introducción de dedos u otras partes del cuerpo

Los requisitos que deben concurrir para que una subsunción de un caso concreto que no se encuentra tipificado expresamente cumpla con las exigencias de un determinado sistema de interpretación son los siguientes: (1) continuidad de la evolución conceptual, (2) arbitrariedad en la valoración que de lo contrario existiría, (3) igual necesidad de regulación, y (4) aptitud para solucionar el problema ${ }^{30}$.

Este sistema de interpretación considera que varias de las interpretaciones sobre determinados elementos típicos, consideradas como analogías prohibidas, realmente cumplen con el principio de legalidad. Así, por ejemplo, resulta lícito para el citado autor subsumir un «camión» en el concepto de vehículo «uncido o de tiro» previsto en la Ley prusiana de hurto forestal, ya que cumple con todos lo requisitos citados, y en especial, respecto de la «continuidad de la evaluación conceptual» y de la «igual necesidad de regulación». Véase que para la posición anterior estaríamos ante una prohibición de analogía en contra del reo ${ }^{31}$.

Analizada someramente esta posición, debemos abordar el caso que nos ocupa, y debemos concluir que tampoco se cumpliría con sus requisitos, y en especial, con el primero de ellos. Las evoluciones conceptuales de «objeto de cualquier índole» y de «animal» en ningún caso pueden considerarse que admitan las partes vivas de un ser humano, claro está, siempre que no nos movamos en el campo de la ciencia ficción ${ }^{32}$. Si se admitiera una interpretación favorable a la inclusión de estas conductas se rompería el sistema de interpretación si se aplicara a otros supuestos análogos. Veamos el art. 374 bis CP. Este precepto establece como objeto típico el «material pornográfico cualquiera que sea su soporte», es decir, en principio objetos inanimados como en el caso del art. 365 bis CP, pero si los extendiéramos al cuerpo humano, tendríamos que considerar dentro de su ámbito típico la exhibición pornográfica de menores de dieciocho años de «carne y hueso», y por tanto, resultaría superfluo la segunda modalidad típica del inciso primero del art. 366 quater CP. Es decir, si consideramos, por ejemplo, los dedos o la lengua como «objetos de cualquier índole» perturbaríamos el sistema de interpretación de los delitos contra la libertad o indemnidad sexual.

Además, como intentaremos fundamentar en la determinación de los bienes jurídicos protegidos en el art. 365 bis CP, la calificación de estos casos como abusos de los arts. 366 o 366 bis CP no supone una «arbitrariedad en la valoración que de lo contrario existiría», ni tampoco conllevaría una «igual necesidad de regulación».

Jakobs, Derecho penal..., cit., p. 85-128.

Roxin, Derecho penal..., cit., p. 152.

Sin embargo, puede existir un caso especial, por cierto bastante macabro, que plantearía una nueva discusión sobre el ámbito de aplicación del art. 365 bis CP. Nos referimos al caso de que se seccione una parte del cuerpo y posteriormente se introduzca en algunas de las cavidades mencionadas en el citado precepto. 
Como conclusión, apreciamos que ninguna de estas dos teorías admitirían la inclusión de partes del cuerpo en el ámbito de aplicación del art. 365 bis CP. Estamos ante un caso de aplicación analógica en contra del reo, es decir, ante una problemática de lege ferenda que debe resolverse en sede legislativa. Sin duda, este caso -debido a las consecuencias políticas, sociales y mediáticas que se derivan de los delitos contra la libertad sexual- pone a prueba el sometimiento de los jueces al principio de legalidad como garantía de los ciudadanos respecto del poder punitivo del Estado.

\section{c) Breve referencia al Derecho comparado}

La cuestión que hemos abordado en el anterior apartado, fue tratada con anterioridad en el Derecho penal español. El CP español de 1995 aglutinó en una misma figura delictiva (art. 179 CP) el acceso carnal y la introducción de objetos, pero omitió la introducción de miembros del cuerpo distintos al pene. Como era de esperar se planteo si la introducción de dedos podría considerarse típica, a lo que respondió negativamente la Sentencia del Tribunal Supremo de 23 de marzo de 1999. Ante esta situación el legislador reformó el citado precepto penal e incluyó expresamente la introducción de «miembros corporales» ${ }^{33}$.

Si bien, debemos rechazar un mimetismo exacerbado respecto de las regulaciones e interpretaciones penales de otros sistemas jurídicos, nuestro legislador penal y, sobre todo, su personal técnico, sin $d u d a$, tuvieron conocimiento de lo acaecido en el Derecho penal español, y por lo tanto, desde el método comparativo de interpretación, tenemos un apoyo adicional para excluir del ámbito de aplicación del art. 365 bis CP la introducción de partes del cuerpo distintas al pene.

Interesante resulta como propuesta de lege ferenda la tipificación de estos supuestos en el Derecho penal alemán. El § 177 StGB en su inciso (2).1 establece como un supuesto grave de coacciones sexuales cuando «el autor realiza el acceso carnal con la víctima o ejerce acciones

33 El art. 179 CP español dispone: «Cuando la agresión sexual consista en acceso carnal por vía vaginal, anal o bucal, o introducción de miembros corporales u objetos por alguna de las dos primeras vías, el responsable será castigado como reo de violación con la pena de prisión de seis a 12 años». Ley Orgánica 15/2003, de 25 de noviembre, por la que se modifica la Ley Orgánica 10/95, de 23 de noviembre del Código Penal. Tras esta última modificación la problemática sobre el ámbito de aplicación del citado precepto se ha centrado, como ya habrá podido adivinarse, en si comprende la introducción de animales o parte de ellos. Una parte de la doctrina sostiene que la referencia típica a la introducción de objetos capta también los casos de introducción de parte de un animal o de un animal entero. Por el contrario, otros autores manifiestan que la posición de los autores citados, atendible desde la perspectiva de la justicia, no se compagina con los criterios jurisprudenciales que requieren el carácter inanimado del «objeto» y por tanto, desborda el marco infranqueable del principio de legalidad. Véase este debate doctrinal en: Gómez Tomillo, Manuel, «Derecho penal sexual y Reforma legal. Análisis desde una perspectiva político criminal», (en) RECPC 07-04, (2005), p. 8. Sin perjuicio de la necesidad de incluir esta modalidad expresamente en el CP español, estamos ante una descripción típica que se adecua en mayor medida al principio de correspondencia con la realidad. 
Los delitos de violación y estupro del artículo 365 bis Código Penal: Una racionalización desde el mandato de lex stricta y el principio de lesividad. Especial referencia a la introducción de dedos u otras partes del cuerpo

sexuales similares con la víctima o se las hace practicar, que sean especialmente humillantes para ésta, especialmente cuando ellas están asociadas con una penetración en el cuerpo (violación) (...). Como puede apreciarse esta figura ha establecido una equiparación material entre el genuino acceso carnal con otras acciones sexuales en consonancia con la efectiva afección al bien jurídico protegido. Así, el legislador penal alemán fundamentó la inclusión de estas modalidades típicas equiparadas al acceso carnal en las idénticas consecuencias traumáticas que conllevan para la víctima. En todo caso, la introducción de dedos no ha estado exenta de una interesante polémica doctrinal. Así, si bien resulta poco discutido y generalmente aceptado que la introducción de objetos en la vagina o en el ano debe calificarse como una conducta sexual especialmente humillante análoga al yacimiento descrita en el delito de violación ${ }^{34}$ (§ 177, párrafo 2, Nr. 1), así como la mayoría de la doctrina rechaza la introducción de objetos en la boca $^{35}$, en el caso de introducción de dedos en la vagina o ano de la víctima resulta especialmente controvertida en la doctrina alemana.

Un fallo del Tribunal Supremo Alemán (BGH) ha entendido como obligatorio la motivación de todas las acciones sexuales análogas al acceso carnal donde se incluye el supuesto crítico de la introducción de un dedo en la vagina de la víctima, a mayor abundamiento, una efectiva comprobación que en el caso particular concurra la especial degradación de la víctima. Así, el citado fallo entendió que no concurría una «especial humillación» en el caso de una introducción de un dedo en la vagina de la víctima, que se realizó por encima del traje de baño y sólo llego a penetrar «un poco el dedo» y duró sólo «unos pocos segundos» ${ }^{36}$. Por el contrario, otros fallos del Alto Tribunal alemán consideran por regla general como «conductas especialmente degradantes» todos los supuestos en que se haya producido una introducción en la vagina o ano de la víctima, y por consiguiente la introducción de un dedo ${ }^{37}$.

Parte de la doctrina alemana mantiene que, de acuerdo al texto de la ley, la característica típica de «especial humillación» resulta superflua e innecesaria en las diferentes formas de introducción ya que el legislador ha establecido estos supuestos expresamente como «especialmente humillantes $»^{38}$. En cambio, otra posición entiende que, por principio, la introducción de dedos en la vagina o el ano no cumple el tipo de violación. Si se tiene en

Por todos, Kieler, Marita, Tatbestandsprobleme der sexuellen Nötigung, Vergewaltigung sowie des sexuellen Mißbrauchs widerstandsunfähiger Personen, Bremen: Juristische Reihe Tenea/www.jurawelt.com Bd.52, (2003), p. 55.

35 Frommel, Monika, «Straftaten gegen die sexuelle Selbsbestimmung», (en) NomosKommentar.Strafgesetzbuch, ( $2^{\mathrm{a}}$ ed.), Nomos Verlagsgesellschaft Baden-Baden, p. 3279. Véase la doctrina y jurisprudencia citada.

36 BGH, NJW 2000, S. 672, 673, (Sala 4 para Asuntos Penales), citada por: Kieler, Tatbestandsprobleme..., cit., p. 56.

37 Véase la doctrina citada por: Kieler, Tatbestandsprobleme..., cit., p. 56.

38 Renzikowski, NStZ 2000, S. 367, 368. Citado por: Kieler, Tatbestandsprobleme..., cit., p. 56. En el mismo sentido, Frommel, «Straftaten gegen die sexuelle...», cit., p. 3279. 
cuenta la gravedad de la pena del $\S 177$ Abs. 2 StGB resulta necesaria una interpretación restrictiva, porque el legislador expresamente ha querido solamente incluir conductas semejantes o análogas al acceso carnal. La cualitativa diferencia del injusto de las relaciones sexuales (acceso carnal) y especialmente por vía anal frente a otras conductas sexuales se manifiesta en un considerable menor riesgo de infección o de embarazo. Pero sobre todo, a causa del intensivo y agravado contacto del autor resulta comparable el contenido del injusto del acceso carnal por vía vaginal, anal o vocal, con otras formas de introducciones, pero no a través de un dedo. No obstante, esta doctrina entiende que, excepcionalmente, podría aplicarse el delito de violación agravado en el caso de una manipulación especialmente grave y dolorosa ${ }^{39}$.

En contraposición de opinión citada, KIELER entiende que semejante diferenciación no es compatible ni con el texto de la ley ni con el derecho a la autodeterminación (sexual). En primer lugar, de acuerdo con el texto de la ley expresamente se mencionan todas las formas de introducción en el cuerpo, siempre y cuando se trate de una conducta sexual especialmente humillante que sea análoga al acceso carnal. El legislador ha destacado (especialmente) esta forma de comisión, porque partió de la especial humillación que por regla general conllevan estas conductas, y por esta razón la aceptación de una cópula análoga se encuentra próxima a una conducta especialmente humillante sin que esté determinado cómo y con qué ha de realizarse tales introducciones ${ }^{40}$. En segundo lugar, el derecho de autodeterminación permite en el caso concreto un diferente contenido del injusto, pero este menor contenido del injusto no se puede deducir de un mayor riesgo de infección o embarazo. El § 177 StGB no protege ni el derecho a la integridad corporal ni el derecho a no quedar embarazada indeseadamente ${ }^{41}$. Con el mismo argumento también resulta incorrecta una interpretación o adaptación en una manipulación grave y dolorosa.

Sin embargo, la autora citada afirma que a primera vista no parece del todo improcedente una diferenciación según la intensidad del contacto corporal. Sin embargo, se presenta aquí la pregunta qué diferencias del injusto deben existir entre la introducción de un dedo y la introducción de un pequeño objeto en la vagina o ano: porque curiosamente en los casos de introducción de objetos la mayoría de la doctrina entiende que debe aplicarse la regla del $\S$ 177 Abs. 2 S. 2 Nr. 1 StGB. En ambos casos existe una introducción en las interioridades de la víctima -comparable con un acceso carnal- y por tanto, en ambos casos se afecta el ámbito esencial de la personalidad de la víctima. Solo debido a que el autor en esta ocasión no se ha

\footnotetext{
39 Folkers, NStZ 2000, S. 471. El autor citado se remite a un caso fallado por el BGH (NStZ-RR 1999, S. 325, Nr. 25), donde un sujeto manipuló de tal manera la vagina de la víctima que le causó un considerable dolor en la zona vaginal. El BGH cualificó la manipulación violenta en la vagina de la víctima como una violación consumada debido a la especial gravedad del injusto de esta conducta. Citado por KIELER, Tatbestandsprobleme, cit., p.57

40 KIELER, Tatbestandsprobleme..., cit., p.59. Véase la doctrina citada por la autora.

41 KIELER, Tatbestandsprobleme..., cit., p.58. Véase la doctrina citada por la autora.
} 
Los delitos de violación y estupro del artículo 365 bis Código Penal: Una racionalización desde el mandato de lex stricta y el principio de lesividad. Especial referencia a la introducción de dedos u otras partes del cuerpo

introducido su propia parte sexual no se puede dejar de considerar estas conductas como especialmente degradantes ${ }^{42}$. De ahí se deriva la presunción de que cualquier introducción en la vagina o el ano debe ser considerada como una conducta especialmente humillante sin que importe si el autor realizó la introducción con un dedo, un objeto o con el miembro sexual.

También comparte esta opinión la Sala 4 para Asuntos Penales del BGH, la cual vincula la presunción de una especial humillación normalmente en toda penetración vaginal o anal. Por regla general, considera como conductas especialmente humillantes todas las conductas que han consistido en una introducción en la vagina o ano y el acceso carnal oral. La anterior conclusión resulta del propio texto de la ley: cualquier conducta sexual especialmente degradante es considerada como análoga al acceso carnal cuando es realizada a través de una introducción ${ }^{43}$.

Después de analizada someramente la doctrina alemana, podemos extraer una importante conclusión: el legislador alemán al no regular expresamente los supuestos de introducciones de dedos como una modalidad comisiva ha generado cierta inseguridad jurídica, precisamente, porque no ha tomado en cuenta el mencionado principio de correspondencia con la realidad. $\mathrm{Si}$ esta modalidad comisiva resulta una de las conductas sexuales más frecuentas en Alemania, debería haberse realizado una mención expresa sobre su calificación típica. No obstante, la expresa referencia a la efectiva lesión del bien jurídico protegido (cualquier conducta especialmente humillante) debería servir de referencia para la necesaria reforma del actual art. 365 bis $\mathrm{CP}$.

\section{Reformulación del bien jurídico protegido}

En el apartado anterior hemos excluido, desde los mandatos del principio de legalidad, la introducción de partes del cuerpo distintas del pene como modalidad típica del art. 365 bis CP, pero entendemos que resulta posible encontrar una fundamentación adicional de carácter material a esta exclusión. Dos son los caminos a seguir.

En primer lugar, de acuerdo con el Informe de la Defensoría Penal Pública, el art. 365 bis CP sólo puede concurrir en el supuesto de que la introducción de objetos "de cualquier índole", por vía vaginal, anal o bucal, o la utilización de animales para realizar tal penetración, posea la misma gravedad que la penetración de un miembro viril. A mayor abundamiento el citado Informe afirma: «De más está decir que debe tratarse de conductas que contengan el necesario grado de lesividad respecto del bien jurídico — libertad o indemnidad sexualescomo para poder estimarlas comprendidas dentro del fin de protección de la norma. Debe tenerse en cuenta, desde una perspectiva teleológica, que debe tratarse de agresiones equivalentes

42 KIELER, Tatbestandsprobleme..., cit., p.58. Véase la doctrina citada por la autora.

43 Véase, BGH, NStZ 2000, S. 254, 255. Citada por: KIELER, Tatbestandsprobleme..., cit., p.59. 
a la violación o al estupro. Así, no podría castigarse conforme a esta disposición la introducción de la lengua o un lápiz en la boca. En definitiva, considerando que toda norma penal lo que pretende es proteger bienes jurídicos, sólo pueden comprenderse aquellos comportamientos creadores ex ante de un riesgo penalmente relevante respecto de aquéllos. Por tanto, deben excluirse las conductas que carecen del necesario grado de lesividad — no concurren las hipótesis que permitan sostener la antijuridicidad material- Sustentar lo contrario, supone poner en entredicho principios básicos de carácter garantista que limitan el ejercicio del ius puniendi» ${ }^{44}$. Así, en el caso de la afección a la indemnidad sexual, la introducción de objetos deberá ser especialmente vejatoria y degradante (por ejemplo, la introducción de una botella).

En segundo lugar, considero que la figura in comento protege, además de los bienes jurídicos protegidos en los delitos de violación y estupro -libertad e indemnidad sexuales- la salud de las personas. La equiparación de penas respecto de los delito de violación y estupro sólo puede fundamentarse en la medida de que la introducción de objetos o animales pueda poner en peligro la salud o integridad física de la víctima. Así, el caso de la introducción de un lapicero en la vagina de una mujer, que no ponga en peligro la salud de la persona, deberá castigarse como un abuso simple. En cambio, la introducción de un objeto que pueda producir una lesión o una infección a la víctima deberá considerarse dentro del ámbito de aplicación del art. 365 bis CP. Establecida esta figura como un delito pluriofensivo, podemos adecuarlo al concepto material del delito y al principio de proporcionalidad de las penas. No obstante, esta propuesta puede entenderse contradictoria con la expresión «objeto de cualquier índole», pero creemos que resulta posible compaginar esta expresión con la lesión o puesta en peligro de los bienes jurídicos protegidos, en el sentido de que sólo será típica la introducción de «objetos de cualquier índole» que ponga en peligro la salud o integridad física de la persona.

En todo caso, si en el ejemplo anterior, la introducción de un lapicero en la vagina, puede ser discutible, en el caso de introducción de objetos en la boca cobra plena vigencia esta propuesta sobre el bien jurídico protegido. Desde una posición de lege ferenda resulta injustificable la equiparación en abstracto de penas entre la introducción de objetos por la vagina o ano y la introducción de objetos por la boca, pero en atención al principio de legalidad debemos interpretar esta modalidad comisiva. Pues bien, la mayoría de introducciones de objetos en la boca no deberán considerarse típicas de acuerdo, no sólo atendiendo al bien jurídico (salud de las personas), sino también a través de los bienes jurídicos de los delitos de estupro y violación (libertad e indemidad sexuales). El art. 366 ter $\mathrm{CP}$, al considerar los abusos como «cualquier acto de significación sexual» ha objetivado la lesión o puesta en peligro de los bienes jurídicos protegidos por estos delitos. Pues bien, para que una introducción de objetos en la boca pueda considerarse típica, conforme al art. 365 bis CP, debe suponer un ataque a la indemnidad sexual, equiparable a la introducción del pene en la boca, y además producir un peligro para la salud de las personas. En otras palabras, una interpretación conforme los criterios derivados del

${ }^{44}$ Defensoría Penal Pública, «Comentarios a la ley $19.927 \ldots »_{s}$ cit., p. 1-2. 
Los delitos de violación y estupro del artículo 365 bis Código Penal: Una racionalización desde el mandato de lex stricta y el principio de lesividad. Especial referencia a la introducción de dedos u otras partes del cuerpo

concepto material del delito debería dejar a esta modalidad típica prácticamente vacía de contenido.

\section{Otras consideraciones típicas}

\section{La tipicidad subjetiva}

Un sector de la doctrina considera que, además del dolo, tanto el delito de violación como el de abusos sexuales requieren un elemento subjetivo del tipo consistente en un ánimo libidinoso o propósito de obtener una satisfacción sexual. Así, los que mantienen esta posición podrán acudir a la falta de este especial ánimo para excluir conductas como, por ejemplo, la introducción de objetos en los órganos genitales realizado por criterios médicos.

Esta posición ha sido criticada, principalmente por dos razones. La primera, porque en la descripción típica de ambas figuras delictivas no se requiere una exigencia subjetiva especial, que en caso contrario supondría una restricción injustificada de la indemnidad sexual. Y la segunda, porque resulta falso que el pretendido ánimo lascivo sea inherente a la propia naturaleza del acto sexual, ya que en caso contrario el intérprete se vería abocado a declarar atípicas conductas motivadas por ejemplo para humillar a la víctima o demostrar la hombría frente a sus pares. Los supuestos, como por ejemplo, el reconocimiento de los órganos genitales por parte de un facultativo, que de acuerdo con esta teoría quedarían fuera del ámbito de aplicación típico debido a la falta de un ánimo libidinoso, deben abordarse desde la tipicidad objetiva. En otras palabras lo que se trata de determinar es si nos encontramos ante un acto sexual, un acto médico o un acto de cualquier otra índole ${ }^{45}$.

Antes de abordar esta interesante cuestión, debe tomarse la siguiente precaución cuando nos enfrentamos ante un concreto supuesto de falta de atipicidad: la falta de una mínima homogeneidad en la doctrina sobre el número de causas de atipicidad y su respectivo ámbito de aplicación. Sin ánimo de exhaustividad, una parte de la doctrina entiende que el bien jurídico protegido no constituye parte del tipo; otros autores agrupan la mayoría de los supuestos de atipicidad en torno a la imputación objetiva; por el contrario, tenemos a quienes atribuyen a la tipicidad subjetiva un papel fundamental en la teoría jurídica del delito, y por ende, en las posibles causas de atipicidad; y por último, incluso parte de la doctrina mantiene que los criterios de imputación objetiva resultan innecesarios ya que los casos que contempla como atípicos encuentran un mejor acomodo dogmático en la falta de dolo o lesión del bien jurídico protegido. Estamos ante uno de los retos de la teoría jurídica del delito, en el sentido de articular un sistema de causas de atipicidad que otorgue, en la medida de lo posible, unos criterios de seguridad jurídica similares a otros elementos o fundamentos de la punibilidad. Ahora bien,

${ }^{45}$ Rodríguez Collao, Los delitos..., cit., p.235. 
mientras tanto o en el caso de que de la propia naturaleza de la tipicidad no resulte posible un sistema más depurado y homogéneo sobre las causas de atipicidad, podemos postular dos criterios de interpretación, uno de orden práctico y otro de orden teórico. El primero, al igual que ocurre con las reglas de interpretación del concurso aparente de leyes, lo importante -a efectos del cumplir con las exigencias derivadas de la función de garantía del principio de tipicidad- radica en determinar si una conducta resulta o no comprendida dentro del ámbito formal y material del tipo penal con independencia de la causa de atipicidad ante la que nos encontremos. El segundo criterio, radica en dar preferencia a las causas de atipicidad objetivas frente a las subjetivas.

Teniendo presentes las anteriores precauciones, si bien resulta correcto afirmar que el tipo subjetivo del art. 365 bis $\mathrm{CP}$ no requiere de un elemento subjetivo del tipo, entiendo que la tipicidad objetiva no resuelve, al menos teóricamente, todos los supuestos de atipicidad en ámbitos sociales especialmente susceptibles de comisión de un delito contra la libertad o indemnidad sexuales. En primer lugar, desde una perspectiva estrictamente teórica la exigencia de dolo presupone la posibilidad de que a pesar de concurrir los elementos objetivos, es decir, la existencia o no de acto médico, la conducta sea atípica. Veamos un ejemplo: Un médico introduce en numerosas ocasiones un instrumento médico en la vagina de una mujer que se ha sentido vulnerada en su libertad o indemnidad sexuales y, además, la práctica del médico no se adecuó a la lex arti. De acuerdo con la posición anteriormente expuesta tendríamos poderosos argumentos para afirmar que nos encontramos ante la figura delictiva in comento. Pero puede suceder que el médico no se representara la lesión del bien jurídico protegido a pesar de su falta de pericia. En otras palabras, si la libertad o indemnidad sexuales constituyen los bienes jurídicos típicos del art. 365 bis $\mathrm{CP}$, la falta de conocimiento de lesionarlos deben calificarse como casos de atipicidad.

\section{El consentimiento de la víctima como causa de atipicidad}

Si bien, la polémica doctrinal sobre la naturaleza jurídica y ubicación del consentimiento en la teoría jurídica del delito mantiene cierta vigencia, apreciamos que la citada discusión doctrinal no afecta al objeto del presente trabajo, ya que tanto las posiciones monistas como dualistas concuerdan que en el caso de delitos sexuales el consentimiento constituye un elemento del tipo penal, y en especial en los delitos de violación y estupro. Así, en el caso de nuestra doctrina nacional, POLITOFF/MATUS/RAMÍREZ afirman que «en ocasiones el consentimiento es inherente al concepto mismo del delito y por ende debe estimarse una característica negativa del tipo; así, en figuras tales como la (...) violación, $\mathrm{N}^{\mathrm{o}} 1$ "cuando se usa fuerza o intimidación»" .

46 Politoff/Matus/Ramírez, Lecciones de Derecho penal chileno. Parte general, (2 ${ }^{\text {a }}$ ed.), Santiago de Chile: Editorial Jurídica de Chile, (2004), p. 240; Luzón Peña, Derecho penal..., cit., p. 560 y 561. 
Los delitos de violación y estupro del artículo 365 bis Código Penal: Una racionalización desde el mandato de lex stricta y el principio de lesividad. Especial referencia a la introducción de dedos u otras partes del cuerpo

El consentimiento como elemento esencial en el art. 365 bis CP podría eludirse a través de una penalización de las lesiones, en especial en los supuestos de sadomasoquismo, donde la eficacia del consentimiento es mucho más discutida ${ }^{47}$. Ahora bien, debemos tener presente que no podrá acudirse a los delitos de lesiones, cuando éstas sean inherentes a la actividad sexual que, en todo caso, deben excluir las lesiones leves y menos graves ${ }^{48}$.

La pregunta acerca de la capacidad que debe exigirse para manifestar el consentimiento en el Derecho penal no puede responderse de forma uniforme, sino que debemos recurrir a la realidad social. Las relaciones sexuales mutuamente consentidas constituyen una de las manifestaciones paradigmáticas del principio de autonomía de la voluntad, por lo tanto, no resulta admisible presumir con carácter general, de acuerdo con una determinada concepción moral de la sexualidad, una mayor capacidad de consentimiento en la introducción de objetos en la vagina, ano o boca de una persona respecto de otras relaciones sexuales.

Debemos tener siempre presente que la capacidad para realizar una relación sexual viene determinada por una determinada concepción ético-social de la sexualidad, que en nuestro caso oscila alrededor de los 16 años de edad. El art. 5. $1^{\circ}$ de la Ley de Matrimonio Civil permite la celebración de un matrimonio a los dieciséis años, situación que conlleva una mayor capacidad de consentimiento que la derivada de una mera relación sexual. A partir de esta afirmación, podemos extraer como principio interpretativo que a partir de los 16 años de edad existen menores posibilidades de que concurra alguna de las causales del estupro. En cambio, en el intervalo de los catorce a los dieciséis, aumenta la posibilidad de que concurra este delito.

\section{La consumación}

A la hora de establecer el momento consumativo de esta figura penal debemos acudir a los tipos de violación propia. El art. 365 bis $\mathrm{CP}$ se entiende consumado de acuerdo con sus distintas modalidades típicas:

a) Introducción de objetos en la vagina. Basta la coniunctio del objeto, no siendo necesaria la immisisio del objeto. De esta forma, el delito se consuma cuando existe un principio de introducción, de modo que se superen los labium maius.

b) Introducción de objetos en el ano. El delito se consuma cuando el objeto traspasa el esfínter.

c) Introducción de objetos en la boca. Si bien abogamos por una aplicación extremadamente restrictiva de esta modalidad típica, su consumación permite apreciar dos interpretaciones. Una mantenida por la Jurisprudencia del Tribunal Supremo español que no requiere traspasar la línea de los dientes; otra, mantenida por parte de la doctrina que postula que

47 La laguna legislativa en esta materia resulta evidente, donde, al menos, debería existir un tipo penal privilegiado.

48 Rodríguez Collao, Los delitos..., cit., p.235. 
el caso anterior debe quedar en grado de tentativa, ya que por boca hay que entender «la cavidad en la cual está colocada la lengua y los dientes cuando existen ${ }^{49}$.

\section{Problemas concursales}

El art. 365 bis CP puede plantear los siguientes problemas concursales:

a) Lesiones. La modalidad de violación impropia realizada por violencia (art. 365. 1 bis en relación con el art. $361.1^{\circ} \mathrm{CP}$ ) puede acarrear unas lesiones a la víctima. En principio, y conforme con la doctrina mayoritaria, las lesiones leves se absorben en la violación consumada $^{50}$. Ahora bien, si nos remitimos a la propuesta del bien jurídico -relativa al peligro a la salud y a la integridad física como fundamento de una mayor severidad penaldebemos plantearnos si conforme con el principio non bis in idem, el art. 365 bis $\mathrm{CP}$ absorbería lesiones más graves, que quedarían, por tanto, en el ámbito de aplicación del art. $69 \mathrm{CP}$.

b) Violación propia del art. $361 \mathrm{CP}$. Especialmente problemáticas resultan las relaciones concursales entre ambas figuras, ya que la introducción de objetos puede ir acompaña de un acceso carnal. Esta situación ha sido resuelta de manera correcta por el legislador español al incluir en un mismo precepto ambas modalidades de agresión sexual. En cambio, el legislador chileno al optar por incluir estas modalidades en otra figura típica plantea la cuestión, al menos formalmente, de qué tratamiento concursal merece la introducción de objetos junta a la del pene.

Si tenemos presente que el núm. 1 del art. 365 bis $\mathrm{CP}$ regula una modalidad de violación, debemos concluir que la introducción de objetos antes o después del acceso carnal debe entenderse consumida, y a lo sumo, tendrá su reflejo penal de acuerdo con el art. 69 CP. Una interpretación favorable a un concurso de delitos, nos llevaría a la siguiente situación: una introducción de un objeto por la boca y un acceso carnal tendrá en abstracto una pena mayor que la introducción de un pene en el ano y la vagina de una mujer. Además véase, que si aplicáramos ambas figuras nos enfrentaríamos a una perplejidad concursal difícil de justificar: se castigaría con penas superiores al homicidio la violación que haya consistido en la introducción, por ejemplo, de un consolador y un pene en la vagina de la víctima. La misma interpretación ha realizado la doctrina nacional respecto de los arts. 361 y $362 \mathrm{CP}$, donde se aprecia siempre un único delito, con independencia del número de circunstancias que concurran o si éstas son tanto del art. 361 como del art. $362 \mathrm{CP}^{51}$.

Serrano Gómez, Derecho penal..., p. 209.

Politoff/Matus/Ramírez, Derecho penal..., cit., p. 263.

Politoff/Matus/Ramírez, Derecho penal..., cit., p. 263. 
Los delitos de violación y estupro del artículo 365 bis Código Penal: Una racionalización desde el mandato de lex stricta y el principio de lesividad. Especial referencia a la introducción de dedos u otras partes del cuerpo

c) Abusos sexuales. De acuerdo con la doctrina respecto del delito de violación propia, cuando concurre junto a un abuso sexual éste se encuentra consumido en aquél. No obstante, parte de la doctrina aboga por el resurgimiento del precepto desplazado (abusos sexuales) en los casos de que la tentativa de violación tenga una menor penalidad ${ }^{52}$. Sin que podamos profundizar en esta cuestión, creemos que estos supuestos son una manifestación de una deficiente técnica legislativa, ya que a la hora de establecer las penas en los delitos sexuales, consciente o inconscientemente, el legislador no comparó sus respectivas penalidades y, por ende, hizo caso omiso del principio de proporcionalidad de las penas. A mayor abundamiento, entendemos que si se demuestra que el sujeto tenía la intención de introducir un objeto, y como paso previo realiza unos abusos, el precepto penal que recoge con mayor exactitud tanto el desvalor del hecho como del resultado es la tentativa de violación. Nuestra posición parte de la premisa que sólo debemos acudir a la regla de alternatividad cuando la problemática concursal no pueda resolverse a través de las reglas concursales destinadas al supuesto de hecho (especialidad, consunción y subsidiariedad), es decir, una regla de consunción no se puede excepcionar por una regla de alternatividad. El denominado resurgimiento del precepto desplazado supone una quiebra del mandato de lex stricta. La solución, por lo tanto, debe encontrarse en sede legislativa que, a modo de propuesta, residiría en el establecimiento de una regla especial de penalidad específica en el delito de violación donde se establezca una remisión a las penas de abusos sexuales -incluso agravada- cuando la tentativa de violación se haya materializado a través de un abuso sexual.

\section{Tratamiento jurisprudencial}

\section{Introducción de partes del cuerpo distintas del pene}

La mayoría de los fallos judiciales han considerado subsumible la introducción de partes distintas del pene en la figura in comento. Incluso, un número importante ni siquiera abordan los problemas de legalidad que plantea la subsunción de estas conductas en el citado precepto.

La sentencias de los TJOP que abordan directamente los problemas de legalidad que plantea la inclusión de la introducción de partes distintas al pene como una modalidad comisiva del art. 365 bis CP, fundamentan su inclusión a través de la teoría subjetiva (voluntad del legislador). Así, la STJOP de Rancagua de 13-9-2003 (RIT 138-2006), expresamente manifiesta:

«Finalmente, cabe mencionar a este respecto que si bien parte de la doctrina nacional (Politoff, Matus y Ramírez) sostiene que no pueden comprenderse dentro del concepto de "objetos de cualquier índole", miembros corporales distintos al pene, fue la propia Comisión de Constitución, Legislación, Justicia y Reglamento del Senado la que dejó constancia, en el

52 Politoff/Matus/Ramírez, Derecho penal..., cit., p. 263. 
estudio del proyecto de la Ley 19.617 que introdujo este articulado, que "el concepto de introducción de objeto de cualquier índole en los conductos vaginales o anales es comprensivo de la utilización de animales para ese efecto, así como cualquier parte del cuerpo humano distinta del órgano sexual masculino, por ejemplo, una mano" (Boletín №2906-07, Primera Sesión de la 350 Legislatura Extraordinaria, página 39). Conforme a dicha interpretación dada por el órgano legislador y que corresponde a la historia fidedigna del establecimiento de la Ley, este Tribunal estimó que los hechos acreditados se ajustan al tipo penal pedido por el Ministerio Público, es decir, se entiende que la introducción de un dedo del acusado en el ano del menor es comprensiva del concepto de introducción de objeto de cualquier índole por vía anal, que tipifica en forma agravada el mencionado artículo 365 bis del Código punitivo».

En el mismo sentido pero añadiendo un discutible criterio gramatical a la fundamentación jurídico-penal la STJOP de Rancagua de 30-7-2005 (Rit 72-2.005) concluye:

«Un sentido natural por el que se inclina el tribunal a la hora de decidir lo que debe entenderse comprendido dentro de la expresión "introducción de objetos de cualquier índole" que utiliza el legislador en el citado artículo 365 bis y que, al mismo tiempo, atiende a lo que se dijo en la historia de la ley, es que con ello se alude a la utilización de cualquier parte del cuerpo humano distinta del órgano sexual masculino, incluyendo, por cierto, los dedos».

Respecto al «sentido natural» entendemos que choca frontalmente no sólo con el sentido técnico-científico de «objeto» sino también con su sentido coloquial. Más bien el «sentido natural» por el que se inclina el TJOP hace referencia a un juicio político criminal sobre la necesidad de incluir esta modalidad comisiva en el art. 365 bis $\mathrm{CP}$, interpretación que, como ya hemos manifestado, atenta directamente contra el mandato de lex stricta.

La STJOP de Antofagasta (RUC Nº. 0200119879-6), si bien no consideró como probado la existencia de una penetración digital, niega la subsunción de la introducción de dedos en el art. 365 bis CP. A continuación reproducimos el obiter dictum que coincide con varios de los planteamientos de la presente investigación y el Informe de la Defensoría Pública ${ }^{53}$ :

«OCTAVO: Como se adelantó en la deliberación, no se estuvo con el Ministerio Público en cuanto pretende que se califiquen los hechos como la figura prevista y sancionada en el artículo 365 bis del Código Penal, consistente en la introducción de objetos, en la especie, por vía vaginal pues, aún asumiendo que una parte del cuerpo humano pueda ser considerada: "objeto de cualquier índole" para efectos de la norma, recogiendo así la historia de la tramitación

53 En la STJOP de 8-9-2006 (RUC: 0500578925-9) la defensa en su alegato de apertura manifestó que los dedos no «son parte de la anatomía humana, no pueden estimarse como objeto. En virtud del principio de legalidad no puede ser acogida esta tipificación» 
Los delitos de violación y estupro del artículo 365 bis Código Penal: Una racionalización desde el mandato de lex stricta y el principio de lesividad. Especial referencia a la introducción de dedos u otras partes del cuerpo

legislativa de la ley en que expresamente se dejó constancia de ello por la Comisión de Legislación y Justicia del Senado, mas, ciertamente, sólo cuando esta figura era considerada dentro del tipo genérico de abuso sexual, agravándolo. En definitiva su consideración final como un delito independiente, equivalente al de violación, con una penalidad similar, sólo puede tener sentido cuando, como finalmente también se dejó constancia en la tramitación legislativa, se produzca efectivamente una suerte de acceso carnal, equiparando la penetración que se produce en la víctima mediante el órgano sexual masculino con aquella que se efectúa mediante objetos.

Luego, para estar ante este delito, necesariamente debe existir penetración vaginal y que la misma constituya un remedo de cópula de suerte tal que con la acción se afecte, además, de la libertad e indemidad sexuales, también la salud de la víctima, requiriéndose, por parte del sujeto activo efectivamente la intención de realizar un acceso vaginal con un objeto distinto del pene».

\section{Otras cuestiones}

El delito de violación impropia ha sido utilizado como una figura residual en los casos en que no se puede demostrar pericialmente la introducción del pene pero sí la de un objeto o miembro. La STJOP de la Serena de 24 de julio de 2006 (ROL: 0500063086-3) manifiesta en su Considerando CUARTO:

«Que los elementos de convicción señalados en el fundamento anterior, apreciados libremente conforme lo dispone el artículo 297 del Código Procesal Penal, fueron bastantes para tener por suficientemente acreditado, más allá de toda duda razonable, desde que no contradicen los principios de la lógica, las máximas de experiencia ni los conocimientos científicamente afianzados, que en horas de la madrugada del día 13 de febrero del año 2005, en el interior de una dependencia del camping Morrillos, ubicado en el kilómetro 432, Coquimbo, el acusado procedió a introducir un elemento contundente en el ano de su hijo Cristofer Eduardo Torres Galleguillos, de dos años y cuatro meses de edad a la fecha, ocasionándole en su ano, tono disminuido, erosión perianal moderada y pliegues con borramiento parcial.

Este hecho es constitutivo del delito, previsto y sancionado en el artículo 365 bis $\mathrm{N}^{\circ} 2$ del Código Penal, en grado de consumado, y en el cual al acusado Walter Torres Heredia le ha cabido participación de autor (...).

Aclaró también el profesional que si bien la erosión perianal y tonicidad disminuida encontradas en el ano del menor, pueden deberse a otras causas, precisó que el borramiento de los pliegues anales, sólo es producido por la introducción de un elemento contundente en el ano, como puede ser un pene en erección u otro objeto ${ }^{54}$. El profesional ilustró al tribunal 
mediante un dibujo, la forma en que observó el ano del menor examinado, el cual estaba expandido, añadiendo que incluso se podía ver materia fecal contenido en el recto del menor, aclarando que aquello, no se produce a raíz de una fuerza de adentro hacia fuera, como sería en el caso de estitiquez, ni por una caída, ya que está conformado de manera tal, que de manera natural se contrae para dar paso al bolo fecal, aún cuando esté endurecido, sin borrar los pliegues anales, sin embargo la fuerza ejercida de afuera hacia adentro con un elemento contundente, contra natura como el caso del menor, esto sin lugar a dudas deja una huella consistente en justamente el borramiento de los pliegues anales, añadiendo, que estos no se recuperan más. La actividad ejercida en la persona del menor, fue suficientemente respaldada por ésta prueba médica directa, que determinó las lesiones encontradas en el ano, acción plenamente compatible con una de las figuras de acción sexual de aquéllas señaladas en artículo 365 bis n² 2 del Código del ramo» ${ }^{55}$.

Otros fallos judiciales ponen en evidencia las dificultades probatorias que supone la verificación de la introducción de los dedos en la vagina de la víctima, ya que el médico legista no puede constatar signos compatibles con una introducción de objetos. En esto casos, sólo cabe acudir a las pruebas sicológicas que permitan su constatación ${ }^{56}$, o en su defecto, calificar la conducta como abusos sexuales ${ }^{57}$.

Este delito comparte la problemática concursal entre los tipos imperfectos de ejecución de violación y los abusos sexuales consumados. La STJOP de 18-11-2004 Antofagasta (R.U.C. $\mathrm{N}^{\circ}$ 0200119879-6) en su considerando calificó el siguiente hecho probado como un delito de abusos consumados del art. 366 bis CP en detrimento de un tipo tentado del art. 365 bis CP.

«La constatación anterior médica fue ratificada con el testimonio del Director del Servicio Médico Legal de esta ciudad, médico-perito Martín Romero Marsilli, que examinó a la niña 48 horas después y que además de la zona escoriativa y equimótica en el vestíbulo derecho pudo observar-aludiendo a su experticia en el tema- un desgarro parcial del himen a nivel de radio 9-10, que era incompleto por cuanto no llegaba a la base de implantación vaginal, lesión que le permitía afirmar que la zona himeneal (explicando que antecede a la vagina) estuvo en contacto con un elemento contundente, sin poder afirmar ni descartar que algún objeto ingresó a la vagina, zona que junto al útero conforman los genitales internos».

También, el delito de violación impropia participa de la problemática concursal de los atentados contra la libertad o indemnidad sexual reiterados, y en especial, en aquellos casos

\footnotetext{
$54 \quad$ Negrita es nuestra.

55 Véase en el mismo sentido: STJOP de Rancagua de 13-9-2006 (RIT 138-2006) y de 14-3-2005 (RIT 04-2005).

56 Véase la STJOP de 18-3-2006 (RUC: 0500273946-3) donde no queda acreditado que la supuesta introducción de los dedos en la vagina de la víctima fuera con anterioridad a la entrada en vigencia de la ley 19.917.

57

Véase la STJOP de Puerto Montt de fecha 28 de junio de 2004
} 
Los delitos de violación y estupro del artículo 365 bis Código Penal: Una racionalización desde el mandato de lex stricta y el principio de lesividad. Especial referencia a la introducción de dedos u otras partes del cuerpo

donde a pesar de verificarse la realización de varias conductas, no se puede precisar ni el número ni la fechas de ellas. Así tenemos algunas sentencias que aplican un solo delito ${ }^{58}$ y otras que acuden al concurso real homogéneo del art. $351 \mathrm{CPP}^{59}$.

\section{Breve referencia al anteproyecto de nuevo código penal}

El Anteproyecto de CP ha subsanado en sus arts. 101 a 103 algunas de las deficiencias descritas en el presente trabajo de investigación. Así, destacamos la mención expresa a la introducción de «partes del cuerpo» como modalidad típica y la exclusión de la boca como vía de acceso apta para realizar la introducción de los objetos o de las partes del cuerpo ${ }^{60}$.

Ahora bien, el citado proyecto mantiene algunas de las carencias y añade otras. En cuanto a las primeras:

a) El APCP mantiene en su esencia la vigente sistematización de esta disfunción social fundamentada en la edad de la víctima. Por el contrario, y junto con la parte de la doctrina más autorizada, postulamos una sistematización estructurada como modalidades comisivas de los delitos de violación y estupro ${ }^{61}$.

b) El APCP equipara la introducción de dedos respecto de otras introducciones de objetos u animales que, debido al peligro que pueden generar a la integridad física o moral, merecen una valoración similar que a la genuina violación o estupro;

Respecto a las nuevas disfunciones destacamos las siguientes:

a) El APCP ha rebajado las penas en todos los supuestos de introducción de objetos. Si bien, desde la óptica de los límites al ius puniendi, por una parte, las penas vigentes resultan claramente desproporcionadas, y por otra parte, resulta preferible que la ley penal establezca un menor rigor penal que el realmente necesario, existen supuestos en que dichas introducciones deben equipararse a la penalidad de la violación o del estupro.

$58 \quad$ La STJOP de Rancagua de 30-7-2005 (Rit 72-2.005) no aplica el art. 351 CPP en supuesto expresamente definido por el Tribunal como «abusos reiterados» y a pesar de que los hechos estaban concretados temporalmente. No obstante, en la determinación de la pena y a través del arbitrio judicial se impuso la misma pena que la acaecida con la subida de un grado e imponiendo la mínima penalidad (una pena de diez años y un día de presidio mayor en su grado medio en relación con la pena en abstracto del núm. 2 del 365 bis CP).

59 Véase las STJOP de: Villarrica de 15-11-2005 (RUC: 0400404395-8), y Rancagua de 13-9-2003 (RIT 1382006).

60 RODRÍGUEZ COLLAO, Luis, «Sobre la regulación de los delitos contra la integridad sexual en el Anteproyecto de Código Penal», (en) Revista Polit. Crim. Al, p. 17.

61 RODRÍGUEZ COLLAO, Luis, «Sobre la regulación...», cit., p. 18. 
b) El proyecto configura en el art. 102 APCP como un tipo cualificado los actos de significación sexual «utilizando animales». Este precepto resulta desafortunado no sólo porque equipara con la misma penalidad la introducción de animales con otras conductas de significación sexual, sino también porque esta agravación se equipara en el caso de los abusos del art. $103 \mathrm{APCP}$ al resto de las circunstancias recogidas en el art. $101 \mathrm{APCP}^{62}$.

\section{Conclusiones}

1. Los mandatos de lex certa y lex stricta-como manifestaciones materiales del principio de legalidad- resultan inherentes al Estado de Derecho, entendido como una garantía material del ciudadano frente al poder punitivo del Estado.

2. A pesar de las anteriores consideraciones, los sucesivos fallos de los TJOP han tipificado la introducción de partes distintas al pene como un delito del art. 365 bis CP. Esta jurisprudencia supone, a mi entender, una quiebra del mandato de lex stricta.

3. Existen varias posibilidades de restricción del extenso ámbito formal del art. 365 bis CP. Una primera posibilidad reside en la función límite del art. 366 ter CP sobre el universo de conductas que formalmente podrían encajar en la descripción típica del art. 365 bis CP. Así, la introducción de objetos de cualquier índole y la utilización de animales tendría que constituir un «acto de significación sexual y de relevancia». Una segunda posibilidad de restricción del ámbito de aplicación del art. 365 bis $\mathrm{CP}$ es acudir a la efectiva concreción de la lesión o puesta en peligro de los bienes jurídicos protegidos en el art. 365 bis CP. Y una cuarta posibilidad radica en la falta de conocimiento de la tipificad objetiva y, en especial, de lesionar el bien jurídico protegido.

4. La correcta calificación jurídico-material en los supuestos de introducción de partes del cuerpo distintas al pene se encuentran en las figuras de abusos sexuales de los arts. 366 y 366 bis CP. La mayor lesividad de estas conductas respecto del resto de los abusos sexuales puede reflejarse en el determinación concreta de la pena (art. $69 \mathrm{CP}$ ).

5. Resulta urgente introducir las siguientes reformas legislativas:

a) Mencionar expresamente la introducción de partes del cuerpo distintas del pene como modalidad típica.

b) Diferenciar aquellos supuestos que valorativamente se equiparen a un acceso carnal. En concreto, aquellos supuestos en que se pueda poner en grave peligro la integridad física de la víctima, o resulten especialmente degradantes.

c) En el supuesto especial de la introducción de dedos, su calificación jurídica como abusos

62 En el mismo sentido, Rodríguez Collao, «Sobre la regulación...», cit., p. 17. 
Los delitos de violación y estupro del artículo 365 bis Código Penal: Una racionalización desde el mandato de lex stricta y el principio de lesividad. Especial referencia a la introducción de dedos u otras partes del cuerpo

sexuales o violación impropia dependerá de la lesión o puesta en peligro de los bienes jurídicos protegidos. Así, la sistematización más correcta sería incluir en el delito de violación, junto a la mención expresa de la introducción de partes del cuerpo distintas del pene, una referencia a la puesta en peligro a la integridad física o su carácter especialmente vejatorio y calificar como abusos sexuales agravados cuando no suponga una puesta en peligro a la integridad física o posea un carácter especialmente vejatorio.

d) La introducción de objetos en la boca debe desaparecer como modalidad típica y dejar su protección a los delitos contra la integridad física o moral. 